\title{
RESEARCH OF PROCESSES AND DEVELOPMENT OF SEPARATORS FOR METAL RECOVERY FROM METALLURGICAL SLAGS
}

\author{
VLADIMIR N. VLASOV \\ State Design Institute Gipromashugleobogashcheniye \\ 30 Pyaterkin St., 348000 Lugansk, Ukraine
}

(Received January 26, 1996, in final form January 30, 1996, accepted March 11, 1996)

\begin{abstract}
This article relates to the analysis of formation and the metal content of slag, generalised data from enterprises on yield and treatment of slags. Test results of the metal content determination in slag dumps, slag granulometric composition, its physical and chemical properties, as well as results of experimental investigation of metal recovery process from slags are presented. Dependences of metal recovery on slagging, granulometric composition and magnetic field parameters of separators were obtained. Electromagnetic separators were developed. Results of technological research carried out under industrial conditions of metal removal from slags, metal scrap cleaning from mineral component are examined in this article.
\end{abstract}

\section{INTRODUCTION}

In connection with the rise in ferrous metal production, the yield of metallurgical slag increases. Considerable quantity of metal is lost in the slag. These losses reduce, to a considerable extent, the yield of high-quality metal and complicate essentially the processing of liquid and solid slags. In particular, presence of metal in the slag creates danger of explosion during the slag granulation, as well as makes worse conditions of crushing and milling of solid slags.

It should, therefore, consider the processing of slags not only from the point of view of the utilisation of its mineral component, but also from the point of view of 
metal removal, as much as possible, with its subsequent utilisation in metallurgy. It applies especially to steel-smelting slags in which the metal content in comparison with blast furnace slags is several times higher.

The practice shows that as a result of insufficient attention to problems of processing of solid steel-smelting slags and of absence of special equipment for their processing and metal removal in slag yards or slag dumps, more than 1.5 million tonnes of metal remains unrecovered annually, while the total yield of steel-making slags in CIS is 22.7 to 22.8 million tonnes. Considerable portion of metal remains in slag and is used for road building wit broken stone. Recovery of metal from slags and its utilisation in metallurgy is one of the most important reserves of raw material.

\section{ANALYSIS OF FORMATION AND METAL CONTENT OF SLAG}

All data obtained from enterprises in the Ukraine on yield and treatment of blast furnace and steel-making slags have been collected and generalised. The yield of blast furnace slags averages about 20.373 million tonnes per annum, and of steel-smelting slags 4.2395 million tonnes. Data were collected and generalised according to the production level (up to 1991).

From physical and chemical properties of slag, of the greatest importance is the fractional composition which is defined by the relationship of different size pieces in a slag, and in the first place by the presence of fine fractions. Of equal importance are the hardness and strength of the slag; these parameters determine its resistance to mechanical action.

Analysis of physical and chemical properties has shown that a solid slag is a hard material of high abrasiveness and strength. These properties have an influence on operation of the production equipment. Specific gravity of slag ranges from 3 to $3.65 \mathrm{~g} / \mathrm{cm}^{3}$, impact resistance $P M 75 \mathrm{~kg} / \mathrm{s} / \mathrm{cm}^{2}$, compression strength 1300 $\mathrm{kg} / \mathrm{s} / \mathrm{cm}$, abrasiveness index over 500. Physical and chemical properties of the converter slags obtained from two plants are shown in Table 1.

Representative samples of slags were selected at some plants in order to determine the metal content of the slag. The sampling was performed from $1 \mathrm{~m}$ length of the 
Table 1 Physical properties of selected slags

\begin{tabular}{|c|c|c|}
\hline Property & $\begin{array}{c}\text { Novolipetsk } \\
\text { Met. Plant }\end{array}$ & $\begin{array}{l}\text { Ilyich Met. } \\
\text { Plant }\end{array}$ \\
\hline Specific gravity $\left[\mathrm{g} / \mathrm{cm}^{3}\right]$ & 3.560 & 3.500 \\
\hline Bulk mass $\left[\mathrm{t} / \mathrm{m}^{3}\right]$ & 1.570 & 1.560 \\
\hline Porosity [\%] & 10.350 & 10.350 \\
\hline Water absorption [\%] & 1.280 & 1.840 \\
\hline Degree of abrasion in drum [\%] & 20.200 & 49.000 \\
\hline Crushability in cylinder [\%] & 9.850 & 8.000 \\
\hline Compression strength $\left[\mathrm{kg} / \mathrm{cm}^{2}\right]$ & $400-1400$ & $400-1400$ \\
\hline Weight loss [\%] & 4.700 & 3.800 \\
\hline
\end{tabular}

conveyor at its several points under different operating conditions and during several days. All selected samples were weighed and then they were subjected to graded crushing and milling. After each stage of crushing, the slag was subjected to magnetic separation. Test results of the metal content determination in the slag dumps are summarised in Table 2.

This it is determined that the slag fed for the secondary treatment contains, on average, $3.03 \%$ of metal from the slag mass.

Slag removed during the secondary treatment of steel-smelting slags has a considerable slag content of mineral component. Slag content of scrap in each fraction is determined by the apparent density method based on density difference of metal shot and slag particles.

In this way, first of all, the sample volume is calculated by volume of water displaced by this sample from the measuring vessel. Then, proceeding from from the sample weight, the prescribed iron weight by volume $\left(7.8 \mathrm{~g} / \mathrm{cm}^{3}\right)$ and the slag weight by volume $\left(2.7 \mathrm{~g} / \mathrm{cm}^{3}\right)$, one can determine the shot volume in this sample.

$$
\mathrm{V}_{\mathrm{Fe}}=\frac{\mathrm{P}_{\mathrm{np}}-2.7 \mathrm{~V}_{\mathrm{b}}}{7.8-2.7}
$$


and after that, the iron content of the sample:

$$
\mathrm{Fe}=\frac{7.8 \mathrm{~V}_{\mathrm{Fe}}}{\mathrm{P}_{\mathrm{np}}} \times 100 \%
$$

where $P_{n p}$ is the sample weight $(\mathrm{kg}), V_{b}$ is the volume of displaced water $\left(\mathrm{dm}^{3}\right)$ and $\mathrm{V}_{\mathrm{Fe}}$ is the volume of iron in the sample $\left(\mathrm{dm}^{3}\right)$.

Table 2 Metal content in assorted slag samples

\begin{tabular}{|c|c|c|c|c|c|c|c|c|}
\hline \multirow{2}{*}{$\begin{array}{c}\text { Sample } \\
\text { mass } \\
{[\mathrm{kg}]}\end{array}$} & \multicolumn{2}{|c|}{$\begin{array}{l}\text { Metal removed } \\
\text { before crushing }\end{array}$} & \multicolumn{2}{|c|}{$\begin{array}{c}\text { Metal removed } \\
\text { after crushing and } \\
\text { milling } \\
\end{array}$} & \multicolumn{2}{|c|}{$\begin{array}{l}\text { Metal content of } \\
\text { the milled slag }\end{array}$} & \multicolumn{2}{|c|}{$\begin{array}{l}\text { Metal content of } \\
\text { slag }\end{array}$} \\
\hline & $10^{-3} \mathrm{~kg}$ & $\%$ & $10^{-3} \mathrm{~kg}$ & $\%$ & $10^{-3} \mathrm{~kg}$ & $\%$ & $10^{-3} \mathrm{~kg}$ & $\%$ \\
\hline 402.000 & $4,710.50$ & 0.470 & $2,839.20$ & 0.280 & $3,862.80$ & 0.380 & $11,412.5$ & 1.110 \\
\hline 14.775 & & & 50.300 & 0.005 & 136.450 & 0.020 & 186.750 & 0.020 \\
\hline 13.260 & & & 36.700 & 0.005 & 230.780 & 0.023 & 267.480 & 0.030 \\
\hline 20.220 & & & 226.150 & 0.020 & 567.080 & 0.060 & 793.230 & 0.080 \\
\hline 13.275 & & & 186.230 & 0.020 & 286.520 & 0.030 & 472.750 & 0.050 \\
\hline 14.625 & & & 153.980 & 0.015 & 245.470 & 0.020 & 399.450 & 0.040 \\
\hline 38.760 & & & 165.580 & 0.020 & 762.190 & 0.080 & 927.770 & 0.090 \\
\hline 39.560 & & & 381.800 & 0.040 & 457.180 & 0.050 & 838.980 & 0.080 \\
\hline 40.780 & & & 551.150 & 0.060 & 673.550 & 0.070 & $1,224.70$ & 0.120 \\
\hline 39.035 & & & 497.300 & 0.050 & 438.920 & 0.040 & 936.220 & 0.090 \\
\hline 69.200 & $1,075.00$ & 0.110 & 703.200 & 0.070 & $1,038.00$ & 0.100 & $4,698.08$ & 0.480 \\
\hline 60.050 & & & 878.380 & 0.090 & 900.750 & 0.090 & 1279,13 & 0.130 \\
\hline 55.300 & & & 693.550 & 0.070 & 553.000 & 0.050 & \begin{tabular}{|l|}
746.550 \\
\end{tabular} & 0.080 \\
\hline 79.500 & & & $1,806.30$ & 0.180 & $1,113.00$ & 0.110 & $2,019.30$ & 0.200 \\
\hline 62.650 & $1,040.00$ & 0.100 & $1,145.30$ & 0.110 & 814.400 & 0.080 & $3,499.70$ & 0.360 \\
\hline 40.000 & & & 612.000 & 0.060 & 600.000 & 0.060 & 712.000 & 0.070 \\
\hline $\begin{array}{c}\text { Total } \\
1003.460\end{array}$ & $6,825.50$ & 0.680 & $10,927.1$ & 1.090 & $12,680.0$ & 1.260 & 30.414 .6 & 3.030 \\
\hline
\end{tabular}


The generalised data of the slag content of scrap are presented in Table 3. The slag content of scrap, taking into account the specific yield, averages $57.5 \%$.

Table 3 Concentration of slag in scrap (in \%)

\begin{tabular}{||c|c|c|c|c|c|c||}
\hline \multirow{2}{*}{$\begin{array}{c}\text { Sample } \\
\text { number }\end{array}$} & \multicolumn{7}{|c||}{ Fraction of scrap [mm] } \\
\cline { 2 - 7 } & +70.00 & $40-70$ & $20-40$ & $10-20$ & $5-10$ & -5.00 \\
\hline 1.00 & 69.10 & 62.00 & 69.09 & 80.50 & 89.10 & 75.40 \\
\hline 2.00 & 49.71 & 59.10 & 67.87 & 74.24 & 72.39 & 84.40 \\
\hline 3.00 & 64.20 & 52.71 & 64.31 & 50.49 & 48.78 & 86.90 \\
\hline 4.00 & 54.50 & 58.70 & 68.50 & 83.78 & 81.01 & 89.30 \\
\hline 5.00 & 49.80 & 54.50 & 71.70 & 79.50 & 86.10 & \\
\hline 6.00 & 46.00 & 48.20 & 46.46 & 44.04 & 83.10 & \\
\hline 7.00 & 48.50 & 36.88 & 38.87 & 77.90 & 56.12 & \\
\hline Average & 54.50 & 53.20 & 60.90 & 70.06 & 78.80 & 84.00 \\
\hline \hline
\end{tabular}

\section{INVESTIGATION OF THE PROCESS OF METAL REMOVAL FROM SLAG}

In existing technological circuits of treatment of metallurgical slags (Novolipetsk Metallurgical Plant, Mariupol Ilyich Metallurgical Plant) standard separators produced for mining and coal industries are used for the metal removal from fractionated crushed stone. During the processing of the slag material these separators do not ensure the maximum removal of metal contained in the slag. To create special electromagnetic separators intended for treatment of metallurgical slag, tests of optimum regimes of the magnetic separation process were carried out with experimental magnetic separation equipment.

Samples used for investigation:

slag sand fractions $-5 \mathrm{~mm}$

scrap and slag crushed stone fractions: $+5-10 \mathrm{~mm},+10-20,+20-40,+40-70$, $+70-150$ and $+150-300 \mathrm{~mm}$. 
The objective of the tests was to formulate preliminary requirements for special separators. During the course of this work the scrap removal was studied as a function of:

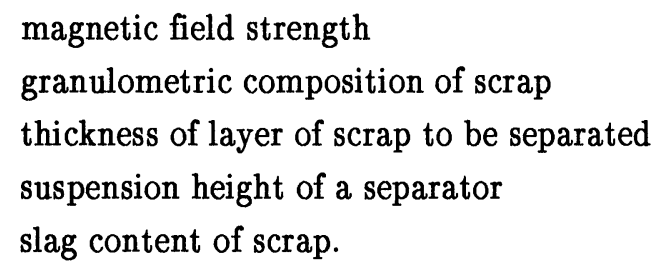

For all scrap fractions, in order to determine the dependence of the efficiency of removal on magnetic field strength, separation was carried out under the following conditions: the samples of the available scrap of a certain mass and of a certain slag content (for fractions of 5-10, 10-20, and 20-40 mm the average slag content of samples was 40 to $45 \%$ ) were placed on a conveyor belt. Scrap samples were disposed at some distance after each other. Scrap samples were fed into the magnetic field of the separator at a slow speed corresponding to the speed of belt movement of production-scale conveyors.

Samples were removed from the zone of the magnet action by a discharging device. The percentage of the scrap removal was determined. Value of the electric current supplying electromagnetic coils was varied in an interval: beginning of the scrap recovery: $100 \%$ of the scrap removal. Suspension height of the electromagnet was $120 \mathrm{~mm}$.

Test results show that the initial magnetic field strength ensuring the beginning of the scrap removal of the above-mentioned fractions is 120 Oersted. $100 \%$ guaranteed scrap recovery of the above mentioned fractions is achieved in magnetic fields with strength that is not less than $400 \mathrm{Oe}$, and for $+5-10 \mathrm{~mm}$ fraction not less than 500 Oe.

Based on the results of the tests, optimum regimes of the magnetic separation process were determined for fractionated crushed stone and sand slag. Taking into account the layer thickness of the separated material which is determined by capacity of the system for treatment of slags and by actual measurements on a conveyor, the suspension height of magnetic separators is calculated on the basis of a double dimension of the slag layer on a conveyor. The best conditions of the separation process are listed in Table 4. 
Table 4 The optimum condition of separation of slag

\begin{tabular}{|c|c|c|c||}
\hline Fraction [mm] & $\begin{array}{c}\text { Thickness of layer } \\
{[\mathrm{mm}]}\end{array}$ & $\begin{array}{c}\text { Height of } \\
\text { suspension [mm] }\end{array}$ & $\begin{array}{c}\text { Magnetic field } \\
\text { strength in } \\
\text { separation zone } \\
{[\text { Oe] }}\end{array}$ \\
\hline-5 & 40 & 80 & 1,000 \\
\hline $5-10$ & 40 & 80 & 800 \\
\hline $10-20$ & 60 & 120 & 620 \\
\hline $20-40$ & 60 & 120 & 520 \\
\hline $40-70$ & 100 & 200 & 600 \\
\hline
\end{tabular}

Determination of the optimum parameters of magnetic induction in the working zone of separator for scrap removal, with maximum particle size of $40 \mathrm{~mm}$, $150 \mathrm{~mm}$ and $300 \mathrm{~mm}$ was performed under production conditions at the Novolipetsk Metallurgical Plant.

To this end, three experimental separators were manufactured in which the magnetic induction was varied over a wide range. As a result of the tests the following values of magnetic induction in the working zone were fixed when the guaranteed scrap recovery took place.

1. Separator for removal of scrap with size $40 \mathrm{~mm}$ :

magnetic induction in the working zone: $0.2 \mathrm{~T}$

power consumption: not more than $2.5 \mathrm{~kW}$

2. Separator for removal of scrap with size $150 \mathrm{~mm}$ :

magnetic induction on the edge of the working zone: $0.29 \mathrm{~T}$ magnetic induction in the middle of the working zone: $0.17 \mathrm{~T}$

3. Separator for removal of scrap with size up to $300 \mathrm{~mm}$ : magnetic induction in the edge of magnetic poles: $0.11 \mathrm{~T}$ magnetic induction on the surface of the working zone: $0.22 \mathrm{~T}$.

Power consumption of these two separators under thermal steady-state conditions did not exceed $13.6 \mathrm{~kW}$. 
The SPSh (СПய)-04/80 electromagnetic separator presented in Fig. 1 is intended for removing magnetic scrap from metallurgical slags with particle size of $40 \mathrm{~mm}$ transported by a belt conveyor.

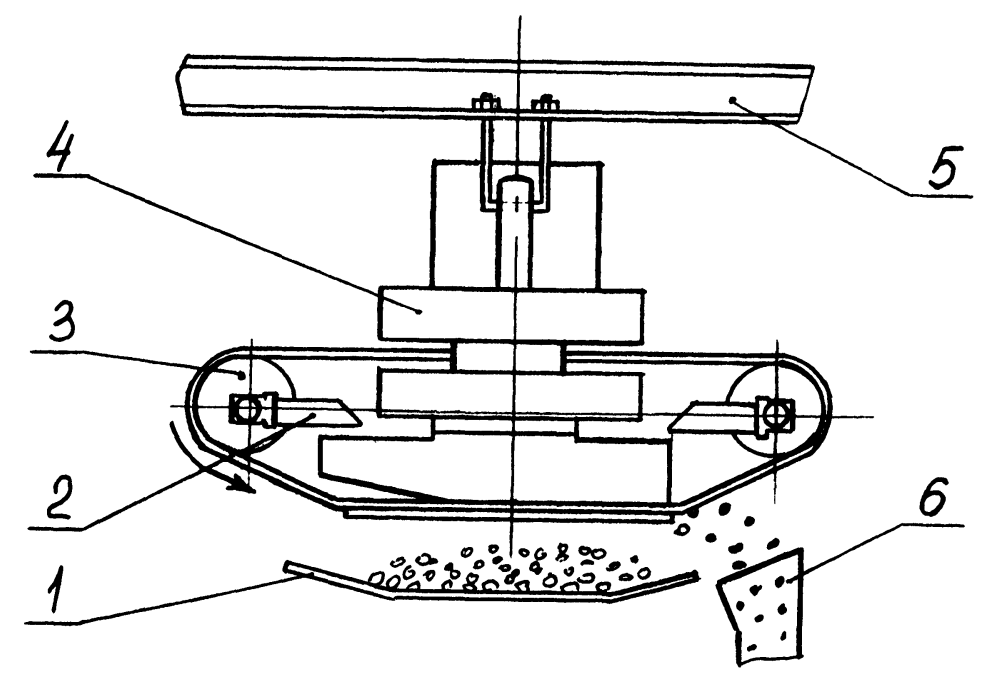

Fig. 1 The SPSh-04/80 electromagnetic separator

The SPSh-04/80 electromagnetic separator consists of an electromagnetic system (4) and a device for discharge of the magnetic product (3). The electromagnetic system (4) comprises a magnetic yoke, excitation coils and pole-pieces of special profile. The device for the discharge of the magnetic product (3) is fixed on the electromagnetic system by means of arms (2). The separator is suspended on frame (5) over the belt conveyor (1) $800 \mathrm{~mm}$ wide for transportation of slag with particle size of $40 \mathrm{~mm}$.

Magnetic product is fed into a zone of the magnet action and is attracted by the magnetic field to the belt of the device for the discharge of the magnetic product and is removed from the zone of the magnetic field action by means of scrapers fixed on the conveyor belt. It is then discharged into the receiving chute (6).

The SKSh-15/100 electromagnetic separator shown in Fig. 2 is intended for removing magnetic scrap from metallurgical slags with particle size of $150 \mathrm{~mm}$ transported by a conveyor belt. SKSh-15/100 electromagnetic separator consists of a frame (5), electromagnetic pulley (1), electromagnetic system (3), drive (2) and discharge device (4) in the form of an endless conveyor belt. 


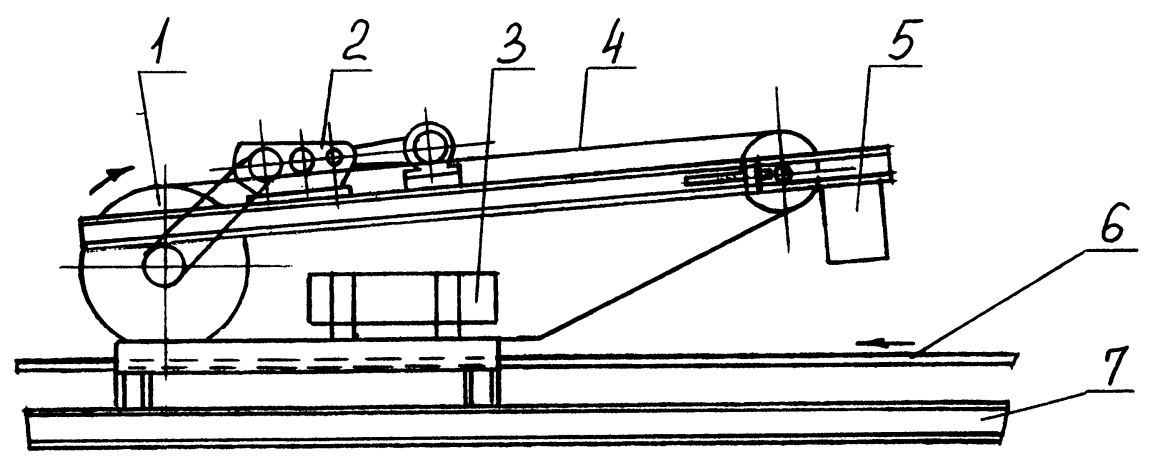

Fig. 2 Schematic diagram of the SKSh-15/100 electromagnetic separator.

The SKSh-115/100 electromagnetic separator is mounted on frame (7) over the conveyor belt (6) $1000 \mathrm{~mm}$ wide, for transportation of slag with particle size of 150 $\mathrm{mm}$. The separator is mounted over the conveyor belt with a small gap between the top edge of the transported slag and the belt surface of the discharging device, as can be seen in Fig. 3. Linear velocities of the conveyor belt and of the discharging device should be equal.

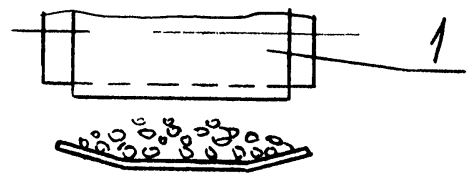

Fig. 3 Position of the conveyor belt with respect to the discharge device.

During the motion on the conveyor belt (6), a raw slag is fed into the action zone of the magnetic field established by the electromagnetic system (3). Due to its action, magnetic scrap is attracted to the belt (4) of the discharge device. Then, by means of the conveyor belt of the discharge device, the scrap moves into the action zone of the magnetic field of the pulley, is attracted to it, moves upwards and is further transported by the belt conveyor into the discharge chute. 
Schematic diagram of the SPSh-30/140 electromagnetic separator is shown in Fig. 4. This separator is intended for removal of metallurgical scrap with particle size of $300 \mathrm{~mm}$. The separator consists of electromagnet (1), frame (2), discharging device (3) and drive (4). The discharging device (3) consists of a belt on which scrapers are fixed, as well as a driving drum and a tension drum. The separator is mounted over the driving (discharging) drum (5) of the belt conveyor $1400 \mathrm{~mm}$ wide, for transportation of raw slag. In order to avoid the shunting of the magnetic field of the separator, the driving drum (5) is made of non-magnetic steel.

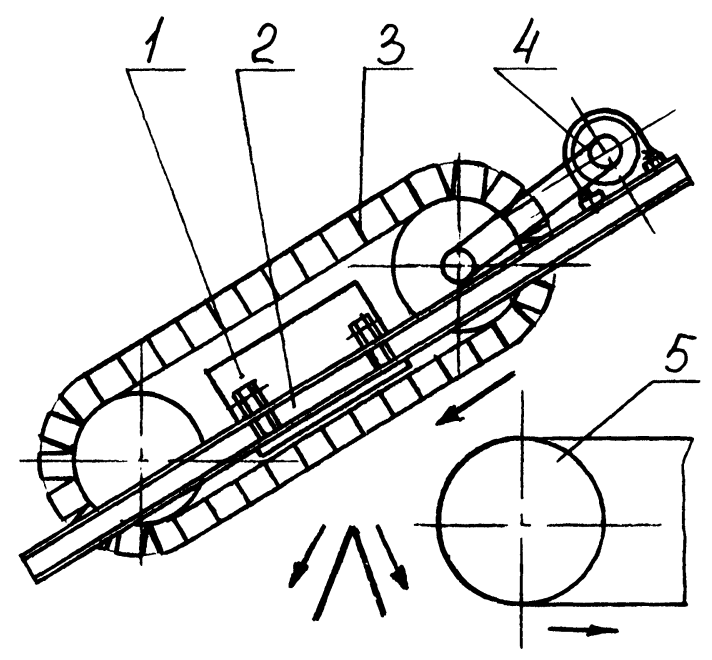

Fig. 4 Schematic diagram of SPSh-30/140 magnetic separator

Magnetic scrap of large size $(300 \mathrm{~mm}$ ) and weight (up to $100 \mathrm{~kg}$ ) is not attracted to the discharging device, and under the action of the magnetic field of the separator it changes its fall trajectory and reaches a scrap chute. The separator operates both in continuous mode and in a mode with metal detector.

\section{RESEARCH OF TECHNOLOGY FOR METALLIC SCRAP CLEANING}

It was established that during the secondary processing of steel-smelting slags by means of a system for treatment of slags, the metal is removed with the slag 
content of about 40 to $50 \%$. For technical and economical reasons it is much more sensible to use steel scrap in steel-making units providing compliance of quality indices of scrap with requirements of regulations which control its use. (The slag content is 10 to $15 \%$ ). Technology of scrap cleaning from a mineral component will raise its metallurgical value.

The efficiency of the scrap cleaning process from mineral components depends on technical specifications of a concrete cleaning mechanism. Tests were carried out under conditions of a production process at Novolipetsk Metallurgical Plant by Niipivtorchermet and Gipromashugleobogashcheniye Institutes. Representative samples of the converter slag removed from a slag were used. In each test samples with the most characteristic slag content for all mass of scrap were selected. The scrap cleaning was performed by using an experimental drum having the following specification:

Internal diameter:

Length of cylindrical part

Diameter of the the feed opening

Rotational speed

Diameter of discharge opening

Capacity
$1200 \mathrm{~mm}$

$4800 \mathrm{~mm}$

$800 \mathrm{~mm}$

$7 \mathrm{rpm}$

$80 \mathrm{~mm}$

$3 \mathrm{t} / \mathrm{h}$

The test results are presented in Table 5. Comparison of the initial and resulting data shows that the scrap cleaning in a drum under the conditions of the tests results in reduction of the slag content to $15 \%$.

On the grounds of the research carried out so far, specifications for systems of equipment for slag treatment were formulated as a whole and for its individual parts.

\section{DEVELOPMENT OF SYSTEMS FOR TREATMENT OF SLAG}

Based on investigations carried out by the Gipromashugleobogashcheniye Institute, systems of equipment KSh-1000 and KSh-75 have been developed for treatment of metallurgical slags (blats-furnace, process, steel works) in slag dumps and from current production. 
Table 5 Results of scrap cleaning tests

\begin{tabular}{|c|c|c|c||}
\hline Sample number & Sample mass $[\mathrm{kg}]$ & \multicolumn{2}{|c|}{ Slag content in scrap [\%] } \\
\cline { 3 - 4 } & & Before cleaning & After cleaning \\
\hline 1 & 2.48 & 59.6 & 16.8 \\
\hline 2 & 6.15 & 54.8 & 11.2 \\
\hline 3 & 2.78 & 28.2 & 11.7 \\
\hline 4 & 16.42 & 35.8 & 14.9 \\
\hline 5 & 19.25 & 41.6 & 10.8 \\
\hline 6 & 5.15 & 32.5 & 9.9 \\
\hline 7 & 4.23 & 45.8 & 13.2 \\
\hline 8 & 11.32 & 38.5 & 14.1 \\
\hline 9 & 8.25 & 41.6 & 11.9 \\
\hline 10 & 9.25 & 37.1 & 10.8 \\
\hline \hline
\end{tabular}

The principle of operation of these systems is based on successive slag screening after crushing with subsequent removal of metallurgical scrap and its slag inclusions in a magnetic field of electromagnetic separators, and on cleaning of the removed scrap from mineral components. The main parameters and overall dimensions of these systems are listed in Table 6 .

Table 6 Specifications of systems for slag treatment

\begin{tabular}{||c|c|c|c||}
\hline Specification & \multirow{2}{*}{$\begin{array}{c}\text { Unit of } \\
\text { measurement }\end{array}$} & \multicolumn{2}{|c|}{ Value } \\
\cline { 3 - 4 } & $\mathrm{kSh}-1000$ & KSh-75 \\
\hline Capacity & $\%$ & 1,000 & 75 \\
\hline $\begin{array}{c}\text { Slag content of the removed } \\
\text { scrap }\end{array}$ & $\mathrm{mm}$ & 30 & 40 \\
\hline Maximum size of scrap & $\%$ & 10 & 10 \\
\hline $\begin{array}{c}\text { Slag content of cleaned metal } \\
\text { scrap }\end{array}$ & & 300 & 250 \\
\hline
\end{tabular}


Each of these systems comprises the following special equipment: receiving hopper with a feeder, tube screen, unbalanced-throw screen, three electromagnetic separators and assembly for scrap cleaning.

The systems should be operated with standard equipment completed and selected by the Institute depending on concrete conditions of the equipment installation. The systems are manufactured by the Lugansk Parkhomenko Machine-building Plant in co-operation with the Gipromashugleobogashcheniye Institute.

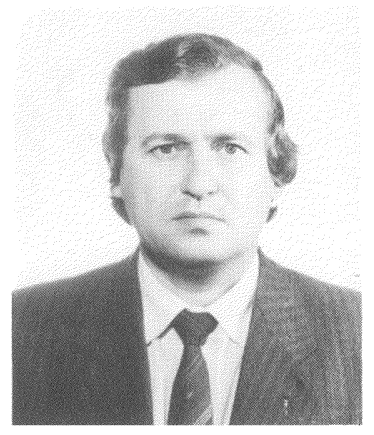

Vladimir Nikolaevich Vlasov was born in 1950 and graduated from the Lugansk Machine-Building Institute. Dr. Vlasov's main interest is the design of magnetic separators and devices for separation of non-magnetic metals and ores and concentration of diamond-bearing raw materials in magnetic liquids. $\mathrm{He}$ is the author of 42 inventions and patents and of 15 papers.

Keywords: slag, metal scrap, magnetic separation, screening 